\title{
Modelling of heat generators: technical standards vs detailed dynamic simulation tools
}

\author{
Franz Bianco Mauthe Degerfeld ${ }^{1, *}$, Giovanna De Luca ${ }^{1}$, Ilaria Ballarini ${ }^{1}$, and Vincenzo \\ Corrado ${ }^{1}$ \\ ${ }^{1}$ Department of Energy “Galileo Ferraris”, Politecnico di Torino, Torino, Italy
}

\begin{abstract}
In the last years, international technical standards have introduced several procedures for modelling the heat generation subsystem, both providing new calculation methods and updating the old ones. A still open issue concerns the modelling of these sub-systems, by adapting the standard procedure - usually founded on simplified assumptions - to the structure of a detailed dynamic simulation tool. In this paper, the main procedures introduced by the international technical standards issued under the Mandate M/480 EN of 2010 on the heat generation sub-systems are presented, with a focus on combustion systems, chillers, and heat pumps. Simplifications and assumptions are analysed, by pointing out the limits related to the simplified modelling based on empirical correlations and tabulated values. The heat generation standardised models are compared with the ones used in detailed simulation tools, such as EnergyPlus. The main differences in the input data and in the model options are presented, and advices for the completion of the information commonly found in technical data sheets are provided. The paper is aimed both at promoting an effective application of the standards in the building design field and at contributing to the standardisation activity for the achievement of more accurate calculation models.
\end{abstract}

\section{Introduction}

Since the publication of the Mandate M/480 EN in 2010 [1] for the elaboration of standards in accordance with the 2010/31/EU directive [2], a new path for the calculation of the energy performance of buildings has been developed, as shown in Fig. 1. New technical standards have been issued, implementing different procedures meant to overcome and improve the existing ones. Compared to the withdrawn standards, remarkable changes have been introduced by the new ones in the modelling of the generation subsystems of the technical building systems. Being relatively recent, studies on the accuracy of the calculation methods and their applicability are still lacking. Some analyses were focused on the withdrawn standards of the previous Mandate [3], as for instance the study of Mattarelli et al. [4], who investigated the variation of the output results caused by the use of default values in place of the real product ones for the generation subsystems.

\footnotetext{
${ }^{*}$ Corresponding author: franz.bianco@polito.it
} 
The new standard procedures are part of a wider group of calculation models commonly applied for the assessment of the building energy performance; they include both the simplified calculation methods - usually employed in the standards - and more complex ones, commonly used in detailed simulation software.

The present work has the purpose to analyse the main procedures provided by the recently issued technical standards and focused on the generation subsystem, deepening their different level of complexity in both modelling aspects and detail of input data. The main procedures employed in some of the most used simulation software, such as EnergyPlus and TRNSYS, are considered as term of comparison. Advices are provided for an effective application of the standards, through the use of accurate input data and reliable modelling assumptions.

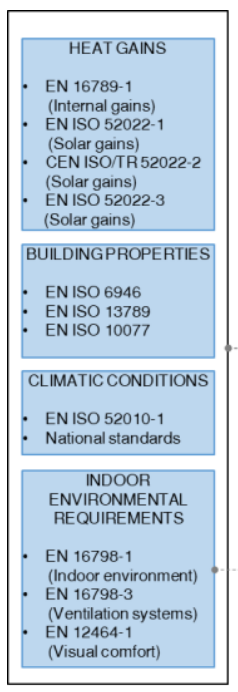

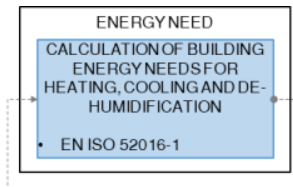

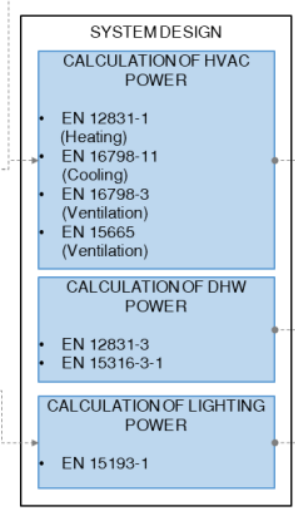

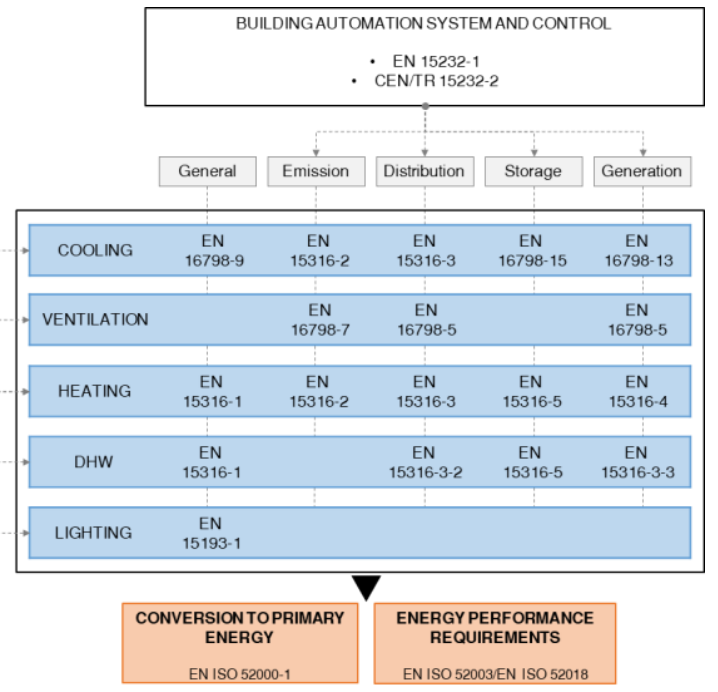

Fig. 1. Regulatory framework under the Mandate M/480 EN of 2010 [1].

The paper has been structured following the steps of analysis. First, the work starts with the study of the main calculation processes available both in the standards and in the simulation software; the main differences in terms of the procedure employed and the simplifications assumed are highlighted (Section 2). Then, the analysis of the input data is performed as to identify the main differences between the methods; difficulties that may occur in case of an excessively detailed input request are discussed (Section 3). Finally, in case this latter condition happens, some advices for the fulfilment of the method requirements are suggested (Section 4).

\subsection{Standardization framework}

To date, the standardization framework relating to generation systems for heating and cooling is not yet fully defined. As regards the heat generation by means of a heat pump, the reference international standard is EN 15316-4-2 [5], the correctness of which is however debated. A replacement module created by the Italian Thermotechnical Committee [6] is being published in Italy, which proposes a method considered more accurate and based on that provided by UNI/TS 11300-4 [7]. For the calculation of cooling generation, specifically for refrigeration units, the EN 16798-13 standard [8] is available and, for combustion heat generation systems, the reference standard is EN 15316-4-1 [9], which is 
currently under review by CEN. Table 1 presents a summary of the regulatory framework, indicating the possible variants available.

Table 1. Regulatory framework for generation systems.

\begin{tabular}{|c|c|c|c|}
\hline Generator & Energy service & $\begin{array}{c}\text { International } \\
\text { standard }\end{array}$ & $\begin{array}{c}\text { Available } \\
\text { variants }\end{array}$ \\
\hline Boiler & Heating and DHW & EN 15316-4-1:2017 & - \\
\hline \multirow{2}{*}{ Heat pump } & Heating and DHW & EN 15316-4-2:2017 & CTI, 2018 \\
\cline { 2 - 4 } & Cooling & EN 16798-13:2017 & - \\
\hline Chiller & Cooling & EN 16798-13:2017 & - \\
\hline
\end{tabular}

\section{Analysis of the calculation methods}

In the following subsections, the calculation methods to assess the heat losses and the energy input of the main generation subsystems - such as boiler, heat pump and chiller are analysed, deepening the main structure of the calculation procedure provided by the technical standards and the simulation software.

\subsection{Boiler}

\subsubsection{Simplified method (International standard procedure)}

The aim of the EN 15316-4-1 standard [9] is to provide a calculation method of the energy performance for heating and domestic hot water systems. The model allows to evaluate the heat losses of the generation subsystem, the recoverable thermal energy for space heating, the consumption of auxiliary energy and the production of domestic hot water.

There are three different calculation methods, which share the same calculation procedure, but differ in the definition of the input data, namely: (i) default values, which are recommended in case of absence of detailed input data on the boilers used, (ii) detailed values, which are recommended in presence of detailed data of the boilers, and (iii) measured values, which can be used for existing traditional and condensing boilers, for verification purposes. The main difference between the three methods lies on the precision of the input values. By using the default values, the only required input is the nominal power output of the boiler, and all the other parameters required for the calculation are derived from empirical formulas and tabulated values. By using the detailed values, all the preliminary calculation is avoided in favour of a complete use of product values given by the manufacturers. By using the measured values, as the name suggests, a complete range of information is used, including the water and flue gases temperatures.

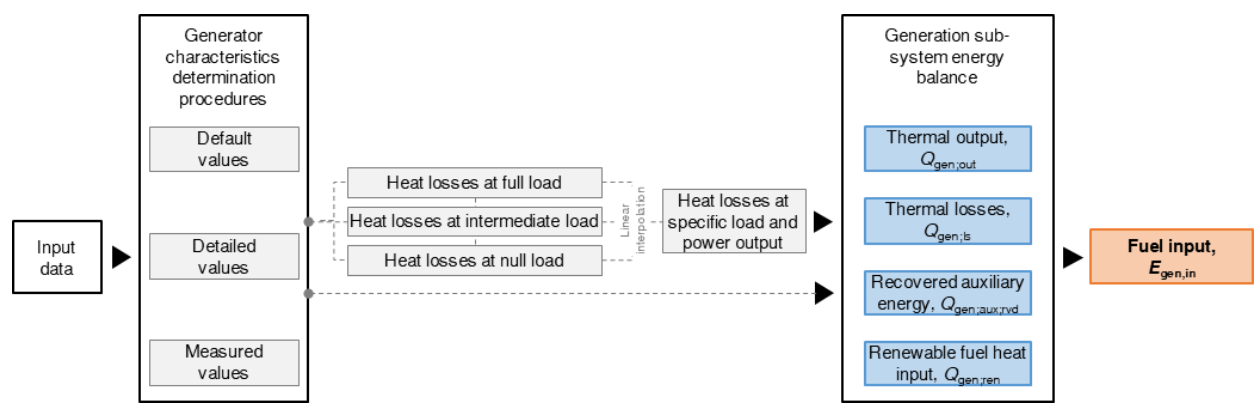

Fig. 2. Calculation method of the generation sub-system for boiler (EN 15316-4-1 [9]). 
As these data are not commonly available, the approach based on measured values is more suited for the efficiency evaluation of existing boilers.

The calculation procedure for a boiler, which is presented in Fig. 2, starts with the determination of the characteristics of the generator, such as the nominal efficiencies at full and partial load. The main approximation performed on the efficiencies consists in the calculation through either a correction factor or a linear interpolation, depending on the considered load and on the typology of boiler, traditional or condensing. Once the calculation of the load factor has been done, the heat losses at specific load are calculated by linear interpolation between the heat losses calculated at full, partial, and null load as expressed in equations (1) and (2).

$$
\begin{aligned}
& \text { If } 0 \leq \beta_{\mathrm{H} ; \mathrm{gen}} \leq \beta_{\mathrm{Pint}} \text { then } \\
& P_{\mathrm{H} ; \mathrm{gen} ; \mathrm{ls} ; \mathrm{Px}}=\beta_{\mathrm{H} ; \mathrm{gen}} / \beta_{\mathrm{Pint}} \cdot\left(P_{\mathrm{H} ; \mathrm{gen} ; \mathrm{ls} ; \mathrm{Pint} ; \text { corr }}-P_{\mathrm{H} ; \mathrm{gen} ; \mathrm{ls} ; \mathrm{P} ; \text { corr }}\right)+P_{\mathrm{H} ; \mathrm{gen} ; \mathrm{ls} ; \mathrm{P} ; \text { corr }}
\end{aligned}
$$

Else if $\beta_{\text {Pint }} \leq \beta_{\mathrm{H} ; \mathrm{gen}} \leq 1$ then

$$
\begin{gathered}
P_{\mathrm{H} ; \mathrm{gen} ; \mathrm{ls} ; \mathrm{Px}}=\left(\beta_{\mathrm{H} ; \mathrm{gen}}-\beta_{\mathrm{Pint}}\right) /\left(\beta_{\mathrm{Pint}}-\beta_{\mathrm{Pint}}\right) \cdot\left(P_{\mathrm{H} ; \mathrm{gen} ; \mathrm{ls} ; \mathrm{Pn} ; \text { corr }}-P_{\mathrm{H} ; \mathrm{gen} ; \mathrm{ls} ; \mathrm{Pint} ; \mathrm{corr}}\right)+ \\
+P_{\mathrm{H} ; \mathrm{gen} ; \mathrm{ls} ; \mathrm{Pin} \text {; corr }}
\end{gathered}
$$

Then, starting from the value of the nominal power of the auxiliary systems and again thanks to an interpolation between characteristic calculated values, the electricity amount used by auxiliaries is assessed. The thermal energy recovered from the heat losses of the generator and that recovered from the operation of the auxiliary systems are calculated as well. By solving the energy balance at the generation subsystem, the last step provides the delivered energy to the boiler.

\subsubsection{Detailed methods (EnergyPlus procedure)}

In EnergyPlus, there are two main procedures for modelling simple hot water and steam generators, respectively. Regarding the former the part load ratio is first calculated as a ratio of the effective load and the nominal capacity, then the fuel used is derived as a function of the effective load and the effective thermal efficiency, as expressed in equation (3).

$$
\text { FuelUsed }=Q_{\mathrm{H}} /\left(\eta_{\mathrm{gen} ; \mathrm{Pn}} \cdot \Delta \eta\right)
$$

The effective thermal efficiency is, in turn, derived from the nominal thermal efficiency multiplied by a correction factor obtained from an efficiency curve. There are several possible curves available in the software: they can be expressed in function either of the part load factor alone or of the part load factor and the boiler inlet or outlet water temperature. The main input required for this procedure are hence the boiler nominal capacity, the nominal thermal efficiency and the output from the efficiency curve. 


\subsubsection{Detailed methods (TRNSYS procedure)}

In TRNSYS, the procedure to model a boiler starts with the determination of the energy required to reach the fluid set point temperature using the water flow rate, inlet temperature and specific heat as expressed in equation (4).

$$
Q_{\mathrm{H}}=V_{\text {water }} \cdot \rho_{\text {water }} \cdot c_{\text {p,water }} \cdot\left(\vartheta_{\text {fluid,in- }} \vartheta_{\text {fluid,set }}\right)
$$

The amount of fuel consumed is simply calculated by dividing the energy transferred to the fluid to the boiler efficiency. Through the combustion efficiency, the energy exhausted from the device and the energy losses are calculated.

This procedure, which appears to be the most simplified one, is only applicable in the case of a correct definition of both the fluid characteristics and the boiler efficiencies. In cases where these latter are not properly analysed, the errors generated with this method are not negligible.

\subsection{Heat pump}

\subsubsection{Simplified method (International standard procedure)}

The EN 15316-4-2 standard procedure [5] is designed for the hourly or bin calculation of the heat generation from heat pumps for space heating, heat pumps for domestic hot water, and heat pumps with combined heating and domestic hot water production. Once the thermal power needed as output from the generator is determined, the first step of the calculation procedure is to define corrective factors that are function of both the inlet evaporator and the outlet compressor temperatures, and are meant to adjust the full load heat pump COP and the nominal capacity at the operative conditions. In order to do that, two different ways are available, path A and path B, as shown in Fig. 3.

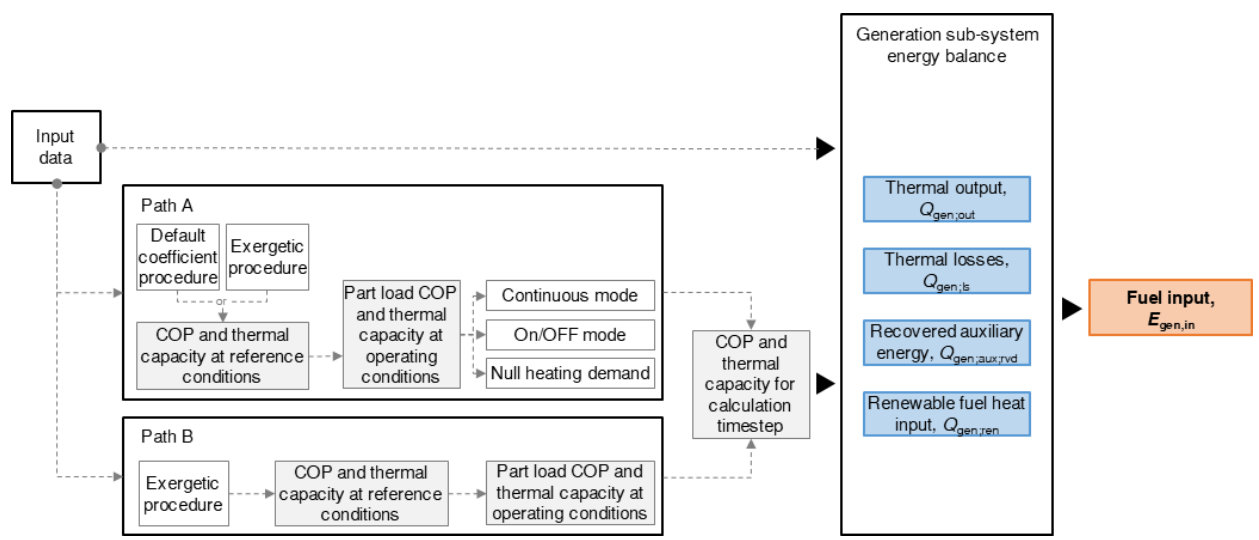

Fig. 3. Calculation method of the generation sub-system for heat pump (EN 15316-4-2 [5]).

In path $\mathrm{A}$, through tabulated values or through a calculation based on Carnot COP ratios, a matrix of coefficients related to various fluid inlet and outer temperatures is defined. The coefficients, in order to take into account the effective fluid temperature, are then corrected through a linear interpolation and multiplied to the nominal COP and maximum load values. Through a comparison with the nominal available power, the heating operating time, first, and the part load factor, then, are calculated. Through this 
latter, depending on the operation mode of the machine - continuous or ON/OFF - the $C O P$ at partial load is calculated as expressed in equations (5) and (6).

$$
\begin{gathered}
f_{\text {gen;LRcont;min;net }}=\left[L R_{\text {cont;min }} \cdot\left(P_{\mathrm{n}}(t)-P_{\text {aux } ; \mathrm{Px}}\right) \cdot t_{\mathrm{ci}}\right] /\left(L R_{\text {cont;min }} \cdot P_{\mathrm{n}}(t)+\right. \\
\left.-P_{\text {aux;Px }} \cdot t_{\mathrm{ci}}\right) \\
C O P_{L R<1}=C O P_{\text {gen;LR100;net }}\left\{\left\{1+\left[\left(f_{\text {gen;LRcont;min;net }-1)(1-L R) /(1+}\right.\right.\right.\right. \\
\left.\left.\left.-L R_{\text {cont,min }}\right)\right]\right\}
\end{gathered}
$$

The procedure of path $\mathrm{B}$ directly corrects the nominal capacity and the full load $C O P$ through the use of a factor that is the ratio of the Carnot $C O P$ in reference conditions to effective conditions.

Once the effective values of thermal capacity and $C O P$ with one of the two paths are determined, the heat losses and the heat recovered from the auxiliary system are calculated. The auxiliary energy is assessed proportionally to the energy used for the operation of the heat pump.

The main uncertainties of the standard method come from the definition of the corrective factors for both the COP and the nominal power which, depending on the path, can be obtained through tabulated and/or calculated values. The calculated ones, that can be used in both A and B paths (presented in Annex D of the standard), come from the calculation of a $C O P$ correction factor defined as the ratio between the Carnot $C O P$ due to temperature conditions in operation and the Carnot $C O P$ due to reference conditions. This procedure starts from the idea that the thermodynamic quality of the process is constant over the entire operating range, thus the properties and the characteristics of the refrigerant fluid are totally neglected. In order to consider this last aspect, an additional procedure is presented, anyhow showing the limit that its equations provide rather an alternative calculation procedure than an improvement of the one presented beforehand. In addition, since some of the terms are not properly defined, a correct application tends to be difficult.

The tabulated values, which can be only used for the path A of the standard, are not free from flaws since some of the characteristic temperatures are repeated more than once with different associated values.

\subsubsection{Simplified method (alternative procedure)}

The alternative procedure, which is presented in Fig. 4, aims to provide a calculation method for the energy required by heat pumps for heating, the production of domestic hot water or combined. The machines considered are absorption heat pumps and vapour compression ones with electric drive or internal combustion engine.

The standard provides for the choice of two different calculation intervals allowing an hourly or per bin calculation. For each calculation interval, there are four different applications: (i) the calculation for the domestic hot water service, (ii) the calculation for the space heating service, (iii) the calculation of the domestic hot water service for systems with BISER heat pump (i.e. hybrid heat pump for the heating and/or the domestic hot water services) in series with another generator, and (iv) the calculation of the heating service for systems with BISER heat pump in series with another generator. 


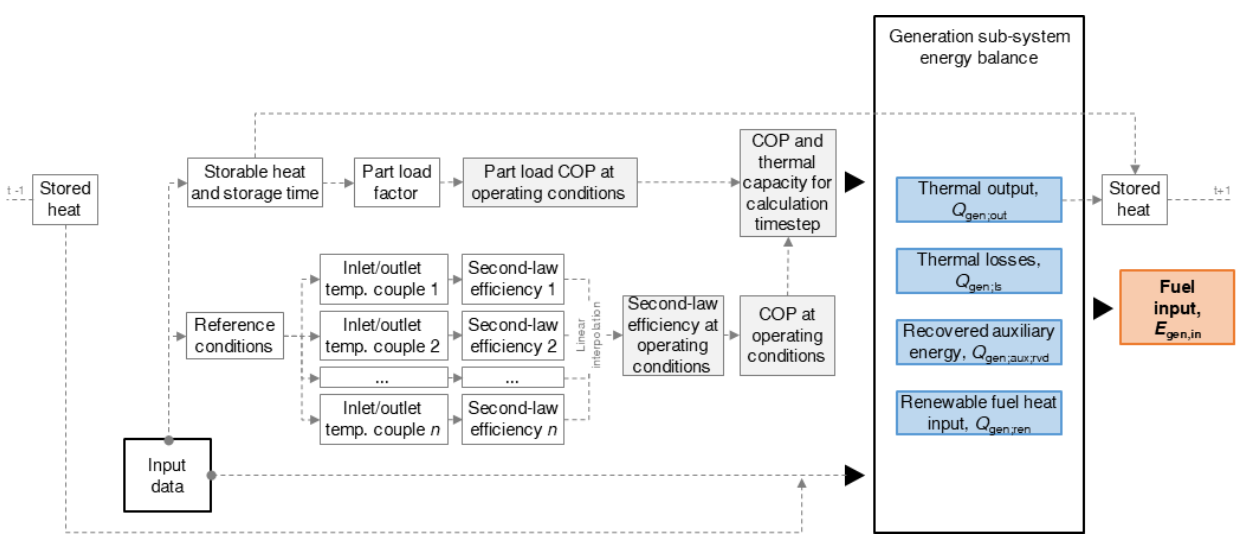

Fig. 4. Alternative calculation method of the generation sub-system for heat pump (CTI [6]).

The model also allows, for each of the services listed, to evaluate: the COP or GUE in actual operating conditions, the input energy required for the operation of the machine for each energy carrier used, the energy extracted from the cold source or recovered from a different cold service of the considered air conditioning system, and the thermal energy recoverable from the internal combustion engine and usable for other services.

The standard provides the calculation procedure for the space heating, whose schedule is summarized as follows. At first, the determination of the energy required by the heat pump is performed, taking into account any energy accumulated in the inertial storage and any energy not supplied in the previous calculation interval; the operating limits of the machine based on the minimum and maximum operating temperatures are checked. Then the effective second principle efficiency, as well as the COP or GUE at full load, are calculated. Through that, it is possible to define the maximum and minimum powers that can be supplied by the machine, according to its performance. Hence the calculation of the coverage of the needs and the related operating time are performed, as well as the calculation of the accumulation capacity and operating time of the inertial tank. The calculation of the load factor $L R$ of the heat pump is then performed as a ratio between the storage and heating time, and the total available time. The actual COP or GUE and the input energy for the operation of the heat pump are finally calculated as expressed in equations (7) and (8).

$$
\begin{gathered}
C O P_{L R<1}=f_{C O P} \cdot\left[\left(\vartheta_{\text {cond;out }}+273,15\right) \cdot\left(\vartheta_{\text {cond;out }}-\vartheta_{\text {evap;in }}\right)\right] \cdot \eta_{\mathrm{II}, i} \\
Q_{\mathrm{H}, \mathrm{pdc}, \text { in,ic }}=\left[\Phi_{\mathrm{H}, \mathrm{pdc}, \text { out }} \cdot\left(t_{\mathrm{H}}+t_{\mathrm{sto}}\right)\right] / C O P_{\mathrm{LR}<1}
\end{gathered}
$$

In this alternative procedure, contrary to the one explained in the previous section, the heat pump efficiency comes from a linear interpolation of the product values which are required at various conditions of both evaporator inlet and condenser outlet temperatures. Through this application, which requires a more detailed definition of the machine characteristics, it is possible to obtain values which are more coherent with the effective behaviour of the system.

\subsubsection{Detailed methods (EnergyPlus)}

In EnergyPlus, several procedures for heat pumps are available depending on the heat source used. In this work, in order to maintain a coherence with the other procedures in 
terms of the fluid considered at the internal side, the attention will be focused on the waterto-water machines. Three different models are available: the parameter estimation based, the equation fit and the EIR-formulated. Since this latter is the most simplified method in term of required input data, and the most similar to the standard one, it will be analysed in detail. The procedure starts with the definition of the load and source flow rate, as well as the inlet temperature for both sides of the machine. Using a curve function of the source inlet temperature and the load side setpoint temperature as outlet temperature, the capacity modifier coefficient is evaluated. Through the latter, the available load side capacity is calculated and with that also the part load ratio. Using this, the actual operating load side heat transfer and the load side outlet temperature are derived. Through the calculation of the EIR curves function of the source inlet temperature, the actual load side outlet temperature, and the current part load ratio are evaluated. Through an energy balance equation on the unit, the source side heat transfer rate and the source side outlet temperature are determined.

\subsection{Chiller}

\subsubsection{Simplified method (International standard procedure)}

The EN 16798-13 standard procedure [8] aims to provide a calculation method for the energy performance of refrigeration units for cooling. The machines considered are compression or absorption refrigeration units and the choice between three different calculation intervals - hourly, monthly or yearly - is allowed. The model evaluates the energy, electrical or thermal, required for the operation of the machine, the recoverable thermal energy and the consumption of auxiliary energy for air conditioning.

There are two different calculation methods, the first one (Method 1, see Fig. 5) has an hourly or per bin calculation interval and is designed for compression or absorption chillers; it is recommended to be used in the presence of detailed data of the machines. The second one (Method 2, see Fig. 6) has an hourly or monthly calculation interval and is designed for the calculation of refrigeration units, split and multi-split, as well as for systems with variable refrigerant gas $(V R F)$. This is recommended in the absence of detailed data of the machines.

\subsubsection{Calculation procedure (Method 1).}

The calculation procedure, which is presented in Fig. 5, starts with the calculation of the general operating condition, i.e. the condenser and evaporator temperatures. Through the comparison between the operating conditions and the required ones, it is determined whether the chiller is in free cooling mode or not. Using the ratio of the corrected nominal to the current Carnot EER, as a correction factor, the maximum heat extraction is obtained. Then, the calculation of the heat extracted by the cooling generation system and the heat recovered or rejected is performed. The equation for the former turns out to be of a difficult application since some of the terms used are not described or defined in the standard. The calculation of the EER coefficient is then performed through a calculation procedure based on the part load factor and other previously calculated data, as shown in equations (9) and (10).

If $L R_{j}>L R_{j ; \min }$ then 


$$
\begin{aligned}
f_{\text {EER } ; j}= & \frac{273,15+\vartheta_{\text {evap;out }}}{\vartheta_{\text {cond; ; }}-\vartheta_{\text {evap;out }}+\left(\frac{L R_{j}}{100}\right) \cdot \Delta \vartheta_{\text {corr } ; j}} . \\
& \cdot\left[C_{1 ; j}\left(\frac{L R_{j}}{100}\right)^{3}+C_{2 ; j}\left(\frac{L R_{j}}{100}\right)^{2}+C_{3 ; j}\left(\frac{L R_{j}}{100}\right)+C_{4 ; j}\right]
\end{aligned}
$$

else

$$
\begin{aligned}
& f_{\text {EER } ; j}=\frac{273,15+\vartheta_{\text {evap;out }}}{\vartheta_{\text {cond;in }}-\vartheta_{\text {evap;out }}+\left(\frac{L R_{j ; \text { min }}}{100}\right) \cdot \Delta \vartheta_{\text {corr } ;}} . \\
& \cdot\left[C_{1 ; j}\left(\frac{L R_{j ; \text { min }}}{100}\right)^{3}+C_{2 ; j}\left(\frac{L R_{j ; \text { min }}}{100}\right)^{2}+C_{3 ; j}\left(\frac{L R_{j ; \text { min }}}{100}\right)+C_{4 ; j}\right]
\end{aligned}
$$

An alternative procedure for the calculation of the EER coefficient can be performed through the use of the nominal EER, as in equation (11).

$$
f_{\text {EER:j }}=\frac{\frac{273,15+\vartheta_{\text {evap;out }}}{\vartheta_{\text {cond;in }}-\vartheta_{\text {evap;out }}}}{\frac{273,15+\vartheta_{\text {evap;out;n }}}{\vartheta_{\text {cond; ; ; n }}-\vartheta_{\text {evap;out; } n}}}
$$

The auxiliary system consumption and the required energy for the compression chillers are then calculated.

One of the issues related to the applicability of this method lies in the calculation of the maximum heat extraction of the generator and in one of the two procedures for the determination of the $E E R$, since this procedures employs terms that come from the solution of a linear system of five equations. This way to proceed causes an increase of both the complexity and the calculation time of the procedure.

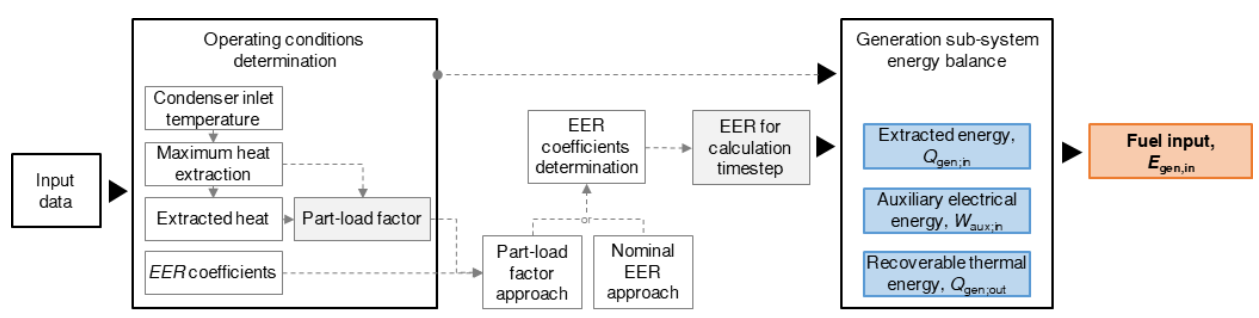

Fig. 5. Calculation method of the generation sub-system for chiller (Method 1 - EN 16798-13 [8]).

\subsubsection{Calculation procedure (Method 2).}

The calculation procedure for a vapour compression refrigeration unit (Fig. 6) starts with the determination of four factors, referred to, respectively, the refrigeration unit, the heat dissipation system, the free-cooling phenomenon and the number of units, which once multiplied lead to the partial load value ( $P L V$ ), as expressed in equations from (12) to (14).

$$
P L V=L R \cdot f_{\mathrm{hr} ; \mathrm{PL}} \cdot f_{\mathrm{hr} ; \mathrm{fc}} \cdot f_{\mathrm{C} ; \mathrm{mult}}
$$




$$
\begin{gathered}
L R=Q_{\mathrm{C} ; \text { gen;in;req }} /\left(t_{\mathrm{C}} \cdot \Phi_{\mathrm{C}}\right) \\
f_{\mathrm{hr} ; \mathrm{PL}}=a_{0}+a_{1} \cdot \vartheta_{e}+a_{2} \cdot \vartheta_{e}^{2}
\end{gathered}
$$

The values referred to the free-cooling and the number of units, are obtained from tabulated values.

The calculation of the correction factor of the energy efficiency ratio is hence performed using the ratio between Carnot $C O P$ calculated in both working and nominal conditions. The calculation of auxiliary energy is performed considering the contribution of the heat rejection, the control and the distribution systems. The thermal energy extracted from the machine and the input energy for the operation of the machine are finally calculated.

In Method 1, the main assumption is on the calculation of the effective capacity load of the chiller, which is calculated through a ratio between the Carnot COP in nominal and operative conditions.

In Method 2, several terms for the calculation of the part load value ( $P L V)$ are obtained through the use of tabulated values determined as a function of the typology of the machine or, as it is for the value referred to the heat rejection system, using a curve.

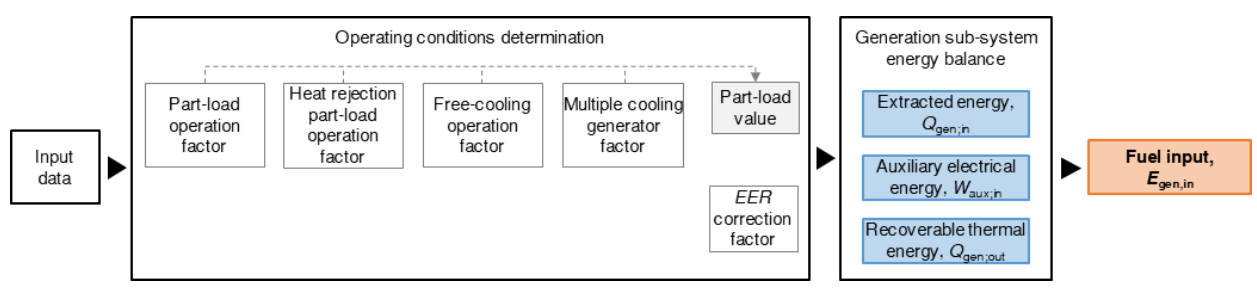

Fig. 6. Calculation method of the generation sub-system for chiller (Method 2 - EN 16798-13 [8]).

\subsubsection{Detailed methods (EnergyPlus procedure)}

There are several chillers available in EnergyPlus that go from the absorption ones to the electric driven ones. Regarding the latter, there are three different types of procedures available that require different input data, i.e. a model based on fluid temperature differences, one based on condenser outlet temperature and one based on condenser inlet temperature. This work will be focused on the latter, which is the closest procedure to the one presented in the EN 16798-13 standard [8].

The calculation procedure starts with the cooling capacity factor which, through a biquadratic performance curve function of the outlet chilled water set-point temperature and the inlet condenser fluid temperature, is derived as expressed in equation (15).

$$
\begin{gathered}
\Delta \Phi_{\mathrm{H}}=a+b \cdot\left(\vartheta_{\mathrm{chw}, \mathrm{set}}\right)+c \cdot\left(\vartheta_{\mathrm{chw}, \mathrm{set}}\right)^{2}+d \cdot\left(\vartheta_{\mathrm{chw}, \mathrm{in}}\right)+e \cdot\left(\vartheta_{\mathrm{chw}, \mathrm{in}}\right)^{2}+f \cdot\left(\vartheta_{\mathrm{chw}, \mathrm{set}}\right) \\
\cdot\left(\vartheta_{\mathrm{chw}, \mathrm{in}}\right)
\end{gathered}
$$

As a function of this latter and the reference chiller capacity, the available chiller capacity and the evaporator outlet water temperature are calculated. The part-load ratio is then calculated as the ratio of the evaporator heat transfer rate to the available chiller capacity, taking in account minimum and maximum values.

Therefore, the variation of the energy input to the cooling output ratio $(E I R)$ is calculated as a function of the temperature and the part-load ratio, through a biquadratic and a quadratic performance curve, respectively. The electrical power consumption of the 
chiller compressors is then determined, as well as the condenser outlet temperature and the condenser fan electrical power.

\subsubsection{Detailed methods (TRNSYS procedure)}

Starting from the input $C O P$ and capacity data, provided for various values of the chilled water set-point temperature and chilled inlet water temperature, the actual $C O P$ is derived through an interpolation. The chiller load is obtained from the chilled water flow rate and the difference between the temperature of the inlet and outlet water, this latter in set point conditions. The part load ratio is derived from the previously calculated load and limited according to the chiller properties. Using a further interpolation, the fraction of full load capacity for operating condition, at first, and the chiller power consumption, then, are calculated as expressed in equation (16).

$$
E_{\mathrm{C}, \mathrm{gen}, \mathrm{el}, \mathrm{in}}=\Phi_{\mathrm{C}} / C O P_{\mathrm{nom}} \cdot F F L P
$$

\section{Differences in the input data}

In the present section, the main input required from each method will be defined and compared in order to analyse the main differences.

\subsection{Input comparison: boiler}

The input required for the methods previously described in Section 2.1, concerning boilers, are presented in Table 2. The principal difference between the input data of the simplified and detailed methods lies within the determination of the efficiency of the boiler. In the first procedure, a single value is required, while in the second one the definition of a curve function of the part load ratio, or both the part load ratio and the water temperature, is needed. This curve is a very precise information of the boiler that is often not provided by the manufacturer, but ensures an enhanced approximation of the real boiler behaviour.

Table 2. Required input data for boilers.

\begin{tabular}{|c|c|c|c|c|}
\hline Input data & $\begin{array}{c}\text { EN 15316-4-1 } \\
\text { (Default values) }\end{array}$ & $\begin{array}{c}\text { EN 15316-4-1 } \\
\text { (Detailed values) }\end{array}$ & EnergyPlus & TRNSYS \\
\hline$f_{\text {gen; } ; \text {; P0 }}$ & $\mathrm{NR}$ & $\mathrm{R}$ & $\mathrm{NR}$ & $\mathrm{NR}$ \\
\hline Fuel Type & $\mathrm{R}$ & $\mathrm{R}$ & $\mathrm{R}$ & $\mathrm{NR}$ \\
\hline$L R_{\text {min,max,opt }}$ & $\mathrm{NR}$ & $\mathrm{NR}$ & $\mathrm{R} / \mathrm{T}$ & $\mathrm{NR}$ \\
\hline$P_{\text {aux; Px }}$ & $\mathrm{R} / \mathrm{T}$ & $\mathrm{R} / \mathrm{T}$ & $\mathrm{R}$ & $\mathrm{NR}$ \\
\hline$P_{\text {int }}$ & $\mathrm{R} / \mathrm{T}$ & $\mathrm{R}$ & $\mathrm{R}$ & $\mathrm{NR}$ \\
\hline$P_{\mathrm{n}}$ & $\mathrm{R}$ & $\mathrm{R}$ & $\mathrm{R}$ & $\mathrm{R}$ \\
\hline$Q_{\mathrm{H}}$ & $\mathrm{R}$ & $\mathrm{R}$ & $\mathrm{R} / \mathrm{T}$ & $\mathrm{NR}$ \\
\hline$V_{\text {water }}$ & $\mathrm{NR}$ & $\mathrm{NR}$ & $\mathrm{NR}$ & $\mathrm{R}$ \\
\hline$\vartheta_{\text {brm }}$ & $\mathrm{R}$ & $\mathrm{R}$ & $\mathrm{NR}$ & $\mathrm{NR}$ \\
\hline$\vartheta_{\mathrm{e}}$ & $\mathrm{R}$ & $\mathrm{NR}$ & $\mathrm{NR}$ & $\mathrm{R}$ \\
\hline$\vartheta_{\text {fluid,in }}$ & $\mathrm{NR}$ & $\mathrm{NR}$ & $\mathrm{NR}$ & $\mathrm{R}$ \\
\hline$\vartheta_{\text {fluid,set }}$ & $\mathrm{NR}$ & $\mathrm{R} / \mathrm{T}$ & $\mathrm{NR}$ & $\mathrm{NR}$ \\
\hline$\vartheta_{\text {gen,test }}$ & $\mathrm{R} / \mathrm{T}$ & $\mathrm{R}$ & $\mathrm{R}$ & $\mathrm{NR}$ \\
\hline$\vartheta_{\text {Hc;mn }}$ & $\mathrm{R}$ & $\mathrm{R}$ & $\mathrm{NR}$ & $\mathrm{NR}$ \\
\hline$\eta_{\text {gen; } \text { Pint }}$ & $\mathrm{NR}$ & $\mathrm{R}$ & $\mathrm{R} / \mathrm{C}$ & $\mathrm{R}$ \\
\hline$\eta_{\text {gen; } \mathrm{Pn}}$ & $\mathrm{NR}$ & & \\
\hline
\end{tabular}

$\mathrm{R}$ required; $\mathrm{R} / \mathrm{T}$ required, default or tabulated values admitted; $\mathrm{R} / \mathrm{C}$ required as a function (curve); NR not required. 


\subsection{Input comparison: heat pump}

The input required for the methods previously described in Section 2.2, concerning heat pumps, are presented in Table 3.

Table 3. Required input data for heat pumps.

\begin{tabular}{|c|c|c|c|}
\hline Input data & EN 15316-4-2 & $\begin{array}{c}\text { EN 15316-4-2 } \\
\text { (alternative procedure) }\end{array}$ & EnergyPlus \\
\hline Condenser type & $\mathrm{R}$ & $\mathrm{R}$ & $\mathrm{R}$ \\
\hline$C O P$ & $\mathrm{R}$ & $\mathrm{R}$ & $\mathrm{R}$ \\
\hline$f_{C O P}$ & $\mathrm{NR}$ & $\mathrm{R} / \mathrm{T}$ & $\mathrm{NR}$ \\
\hline$Q_{\mathrm{H}}$ & $\mathrm{R}$ & $\mathrm{R}$ & $\mathrm{R}$ \\
\hline$P_{\text {aux; } \mathrm{Px}}$ & $\mathrm{R}$ & $\mathrm{R}$ & $\mathrm{R}$ \\
\hline$P_{\mathrm{n}}$ & $\mathrm{R}$ & $\mathrm{NR}$ & $\mathrm{R}$ \\
\hline$\Delta E E R$ & $\mathrm{NR}$ & $\mathrm{R}$ & $\mathrm{R} / \mathrm{C}$ \\
\hline$\Delta \vartheta_{\mathrm{f}-\mathrm{c}, \min }$ & $\mathrm{NR}$ & $\mathrm{NR}$ & $\mathrm{NR}$ \\
\hline$\Delta \Phi_{\mathrm{H}}$ & $\mathrm{NR}$ & $\mathrm{NR}$ & $\mathrm{R} / \mathrm{C}$ \\
\hline$\vartheta_{\text {cond;in }}$ & $\mathrm{R} / \mathrm{T}$ & $\mathrm{NR}$ & $\mathrm{R}$ \\
\hline$\vartheta_{\text {cond;out }}$ & $\mathrm{R}$ & $\mathrm{R}$ & $\mathrm{R}$ \\
\hline$\vartheta_{\text {cond;out,max } / \text { min }}$ & $\mathrm{NR}$ & $\mathrm{NR}$ & $\mathrm{NR}$ \\
\hline$\vartheta_{\text {evap;in }}$ & $\mathrm{R} / \mathrm{T}$ & $\mathrm{R}$ & $\mathrm{R}$ \\
\hline$\vartheta_{\text {evap;in, } \text { max } / \min }$ & $\mathrm{NR}$ & $\mathrm{NR}$ & $\mathrm{NR}$ \\
\hline$\vartheta_{\text {evap;out }}$ & $\mathrm{R}$ & $\mathrm{C}$ & $\mathrm{R}$ \\
\hline
\end{tabular}

$\mathrm{R}$ required; $\mathrm{R} / \mathrm{T}$ required, default or tabulated values admitted; $\mathrm{R} / \mathrm{C}$ required as a function (curve); $\mathrm{NR}$ not required.

The principal difference between the input data of the simplified and detailed methods lies in the determination of the efficiency and the maximum power available of the heat pump. In both standard and alternative methods, product default values are required. While in the first one only a single value is needed, in the second one several values defined for various reference conditions are necessary, thus causing an increase both of product data and of precision.

In the EnergyPlus simulation engine, the requirement goes to an upper level of precision with the request of all inlet and outer temperatures for the condenser and evaporator, together with the definition of a characteristic curve for the performance and the energy output of the heat pump. These requests define a very complex input that is often difficult to be clearly defined and that can lead to not negligible errors in the results if not properly identified.

\subsection{Input comparison: chiller}

The input required for the methods previously described in Section 2.3, concerning chillers, are presented in Table 4. 
Table 4. Required input data for chillers.

\begin{tabular}{|c|c|c|c|c|}
\hline Input data & $\begin{array}{c}\text { EN 16798-13 } \\
\text { (Method 1) }\end{array}$ & $\begin{array}{c}\text { EN 16798-13 } \\
\text { (Method 2) }\end{array}$ & EnergyPlus & TRNSYS \\
\hline Chiller flow mode & $\mathrm{R}$ & $\mathrm{R}$ & $\mathrm{R}$ & NR \\
\hline $\begin{array}{l}\text { Condenser Fluid } \\
\text { Flow Rate }\end{array}$ & NR & NR & $\mathrm{R} / \mathrm{T}$ & NR \\
\hline Condenser type & $\mathrm{R}$ & $\mathrm{R}$ & $\mathrm{R}$ & NR \\
\hline$C O P_{\text {ref }}$ & NR & NR & NR & $\mathrm{R}$ \\
\hline$E E R_{\mathrm{n}}$ & NR & $\mathrm{R}$ & $\mathrm{R}$ & NR \\
\hline$L R_{\min , \max }$ & NR & NR & $\mathrm{R} / \mathrm{T}$ & NR \\
\hline$P_{\text {aux }: \mathrm{Px}}$ & $\mathrm{R}$ & $\mathrm{R}$ & $\mathrm{R}$ & NR \\
\hline$P_{\mathrm{el}, \mathrm{C}, \mathrm{ctrl}}$ & $\mathrm{R}$ & $\mathrm{R}$ & $\mathrm{R}$ & NR \\
\hline$P_{\mathrm{hr} ; \mathrm{el}}$ & $\mathrm{R}$ & $\mathrm{NR}$ & $\mathrm{R} / \mathrm{T}$ & NR \\
\hline$P_{\mathrm{n}}$ & $\mathrm{R}$ & $\mathrm{R}$ & $\mathrm{R}$ & NR \\
\hline$Q_{\mathrm{C}}$ & $\mathrm{R}$ & $\mathrm{R}$ & $\mathrm{R}$ & NR \\
\hline$V_{\text {water }}$ & NR & NR & $\mathrm{R} / \mathrm{T}$ & $\mathrm{R}$ \\
\hline$\triangle E E R$ & NR & NR & $\mathrm{R} / \mathrm{C}$ & NR \\
\hline$\Delta \vartheta_{\mathrm{fc}}$ & $\mathrm{R}$ & NR & NR & NR \\
\hline$\Delta \Phi_{\mathrm{C}}$ & NR & NR & $\mathrm{R} / \mathrm{C}$ & $\mathrm{R} / \mathrm{C}$ \\
\hline$\vartheta_{\text {chw,in }}$ & NR & NR & NR & $\mathrm{R}$ \\
\hline$\vartheta_{\mathrm{chw}, \mathrm{set}}$ & NR & NR & NR & $\mathrm{R}$ \\
\hline$\vartheta_{\mathrm{C} ; \text { gen;out } ; \mathrm{n}}$ & $\mathrm{R}$ & $\mathrm{R} / \mathrm{T}$ & $\mathrm{R} / \mathrm{T}$ & $\mathrm{R}$ \\
\hline$\vartheta_{\text {cond;in }}$ & $\mathrm{R}$ & NR & NR & $\mathrm{R}$ \\
\hline$\vartheta_{\mathrm{e}}$ & $\mathrm{R}$ & $\mathrm{R}$ & $\mathrm{R} / \mathrm{T}$ & NR \\
\hline$\vartheta_{\mathrm{e}, \mathrm{wb}}$ & $\mathrm{R}$ & NR & NR & NR \\
\hline$\vartheta_{\text {evap;out }}$ & $\mathrm{R}$ & NR & NR & NR \\
\hline$\vartheta_{\text {evap:out,n }}$ & $\mathrm{R}$ & NR & NR & NR \\
\hline
\end{tabular}

$\mathrm{R}$ required; $\mathrm{R} / \mathrm{T}$ required, default or tabulated values admitted; $\mathrm{R} / \mathrm{C}$ required as a function (curve); NR not required.

In this case, since the procedures vary a lot from each other, there are several differences in the input required. The main difference between the input data of the simplified and detailed methods lies in the determination of the efficiency and the capacity of the chiller. In the first procedure, in fact, since the calculation of these latter parameters is performed through corrective coefficients, only default values are required. On the contrary, in the dynamic procedure, three different curves are required for the calculation. The other differences, such as the chilled flow rate or the part load ratio limits, can be avoided through the use of default values.

\section{Advices for the completion of the information}

From the comparison between the calculation models and the different types and detail levels of input data, some advices are provided for an effective application of the standard methodologies. In addition, suggestions are given as to complete the framework of missing information.

Regarding the main differences in the input data, some of them required by the standard calculation procedures are not usually available in the product data or in the environment data. For what concern the product, the main differences lie in the determination of the performance characteristics, i.e. the efficiency and the available power load, for the various operating conditions. While the simplified methods only require one or more default values, the detailed methods need the definition of curves that can describe the actual values in each possible operative condition. 
Since product detailed data are not often available, the most viable way is to interpolate, starting from a small group of default data referred to few default conditions and creating curves that can approximate in a correct manner the actual behaviour of the generation system. In the cases where the available data are only limited to a single value, a way to proceed may be the use of available characteristic curves designed for generators that have similar characteristics.

In some of the analysed standards, especially in EN 15316-4-2 [5] and EN 16798-13 [8], several equations contain terms with wrong subscripts or without a proper definition. While performing the calculation using these standards, it is very important to analyse one by one the equations, in order to fully understand their meaning and overcome the errors they may contain.

\section{Conclusions}

The analysis of the calculation procedures carried out for the three types of generation systems considered - boilers, heat pumps and chillers - highlighted several differences between the methods presented in the technical standards recently issued.

The major issue concerns the input data, which are usually required with a different level of detail. Whereas the level is high, a limitation occurs due to the restricted product related information commonly provided by the manufacturer.

The standards analysed, especially EN 15316-4-2 [5] and EN 16798-13 [8], still contain several inaccuracies in the formulas and in the tabulated values with repeated values and terms not properly defined; because of that, a complete application of these standard turns out to be difficult.

A further necessary improvement may be the definition of characteristic performance curves for each typology of generation system, as in the detailed energy simulation tools. These curves should be related to a single value of efficiency and maximum load, in order to be applied even in case of an extremely limited available input, and should offer reasonable approximation of the real behaviour of the product.

At the moment, studies aimed at increasing the accuracy of simplified models through the comparison between standard methods and detailed simulation tools presents high limits of applicability. Despite the effort to align input data by means of modelling consistency options, the still large uncertainty of data on the properties of generation systems in technical standards and the use of assumptions cause issues on the results comparison.

\section{Symbology}

$\begin{array}{ll}C_{1-4 ; j} & \text { Coefficient of the chiller } j, \mathrm{ND} \\ C O P_{\text {gen;LR100;net }} & \text { Heat pump net } C O P \text { at full load, ND } \\ C O P_{L R<1} & C O P \text { at specific load, ND } \\ C O P, \text { nom } & \text { Nominal } C O P \text { at operating conditions, ND } \\ C O P, \text { ref } & C O P \text { at standard rating conditions at full load, ND } \\ c_{\mathrm{p}, \text { water }} & \text { Specific heat of the water, } \mathrm{kJ} / \mathrm{kg} \\ E_{\mathrm{C}, \mathrm{gen}, \mathrm{el}, \mathrm{in}} & \text { Cooling generation electrical energy input, kWh } \\ E E R_{\mathrm{n}} & \text { Nominal energy efficiency ratio, ND } \\ f_{\mathrm{C} ; \text { mult }} & \text { Factor for multiple refrigeration units, ND } \\ f_{C O P} & C O P \text { correction factor, ND } \\ f_{E E R ; j} & \text { Correction factor of the } E E R \text { at current calculation interval, ND } \\ f_{\text {gen; }: L R \text { cont;min;net }} & C O P \text { correction factor for heat pump at part load, ND } \\ f_{\text {gen;ls:P0 }} & \text { Stand-by heat losses, ND } \\ f_{h r ; \text {;c }} & \text { Chiller free cooling factor, ND } \\ f_{h r ; \mathrm{PL}} & \text { Chiller part load factor of the heat rejection system, ND }\end{array}$


FFLP

$L R$

$L R_{\text {cont:min }}$

$L R_{j ; \min }$

$L R_{\text {min,max,opt }}$

$P_{\text {aux } ; \text { Px }}$

$P$ el,C,ctrl

$P_{h r ; e l}$

$P_{\mathrm{H} ; \mathrm{gen} ; \mathrm{ls} ; \mathrm{Px}}$

$P_{\mathrm{H} ; \mathrm{gen} ; \mathrm{ls} ; \mathrm{Pn}}$

$P_{\mathrm{H} ; \mathrm{gen} ; \mathrm{ls} ; \text { Pint }}$

$P_{\mathrm{H} ; \mathrm{gen} ; \mathrm{ls} ; \mathrm{P} 0}$

$P_{\text {int }}$

$P_{\mathrm{n}}$

$Q_{\mathrm{H} / \mathrm{C}}$

$Q_{\mathrm{H}, \mathrm{pdc}, \mathrm{in}, \mathrm{ic}}$

$t_{\mathrm{C}}$

$t_{\mathrm{ci}}$

$t_{\mathrm{H}}$

$t_{\text {sto }}$

$V_{\text {water }}$

$\beta_{\mathrm{H} ; \mathrm{gen}}$

$\beta$ Pint

$\beta$ Pn

$\Delta \vartheta_{f-c, \min }$

$\Delta \eta$

$\Delta \Phi_{\mathrm{H}, \mathrm{C}}$

$\triangle E E R$

$\Delta \vartheta_{\text {corr } ; j}$

$\Delta \vartheta_{\mathrm{fc}}$

$\eta$ combustion

$\eta_{\text {gen;Pint }}$

$\eta_{\text {gen;Pn }}$

$\eta_{\mathrm{II}, i}$

$\vartheta_{\text {brm }}$

$\vartheta_{\mathrm{C} ; \mathrm{gen} ; \text { out;n }}$

$\vartheta_{\text {chw,in }}$

$\vartheta_{\text {chw,set }}$

$\vartheta_{\text {cond;in }}$

$\vartheta_{\text {cond;in;n }}$

$\vartheta_{\text {cond;in,max/min }}$

$\vartheta$ cond;out

$\vartheta_{\mathrm{e}}$

$\vartheta_{\text {evap;in }}$

$\vartheta_{\text {evap;out }}$

$\vartheta_{\text {evap;out,n }}$

$\vartheta_{\text {evap;out, max/min }}$

$\vartheta_{\mathrm{e}, w b}$

$\vartheta_{\text {fluid,in }}$

$\vartheta_{\text {fluid,set }}$

$\vartheta_{\text {gen;in;ref }}$

$\vartheta$ gen;out;ref

$\vartheta_{\text {gen,test }}$

$\vartheta_{\mathrm{Hc} ; \mathrm{mn}}$
Fraction of full-load power for chiller, ND

Effective part load ratio, ND

Minimum load factor for the compressor

Minimum part load ratio of the chiller $j$, ND

Minimum, maximum and optimum part load ratio, ND

Power consumption of auxiliary equipment, $\mathrm{kW}$

Electric power consumption of control device (sensor, actuators, controllers), $\mathrm{kW}$

Electrical power consumption of the heat rejection system, $\mathrm{kW}$

Boiler losses at specific load, $\mathrm{kW}$

Boiler losses at full load, $\mathrm{kW}$

Boiler losses at intermediate load, $\mathrm{kW}$

Boiler losses at null load, $\mathrm{kW}$

Generator output at intermediate load, $\mathrm{kW}$

Generator output at full load, $\mathrm{kW}$

Required thermal energy, $\mathrm{kW}$

Input energy for the heating pump, $\mathrm{kWh}$

Effective running time for cooling, $\mathrm{h}$

Duration of the time step for the calculation, $h$

Effective running time for heating, $h$

Storage time, $\mathrm{h}$

Design water flow rate, $\mathrm{m}^{3} / \mathrm{s}$

Boiler actual load ratio, ND

Boiler load ratio at intermediate load, ND

Boiler load ratio at nominal conditions, ND

Minimum difference between condenser inlet temperature and evaporator outer temperature, $\mathrm{K}$

Generator efficiency variation, ND

Nominal thermal power variation, ND

Nominal energy efficiency ratio variation, ND

Correction temperature difference of the chiller $\mathrm{j}, \mathrm{K}$

Free cooling operation temperature difference limit, $\mathrm{K}$

Combustion efficiency, ND

Generator efficiency at intermediate load, ND

Generator efficiency at full load, ND

Second law efficiency for every considered evaporator inlet and condenser outlet temperatures combination $i$, ND

Ambient temperature, ${ }^{\circ} \mathrm{C}$

Nominal cooling generation output temperature, ${ }^{\circ} \mathrm{C}$

Chilled water inlet temperature, ${ }^{\circ} \mathrm{C}$

Chilled water set-point temperature, ${ }^{\circ} \mathrm{C}$

Condenser inlet temperature, ${ }^{\circ} \mathrm{C}$

Condenser inlet temperature at nominal conditions, ${ }^{\circ} \mathrm{C}$

Maximum/minimum condenser inlet temperature, ${ }^{\circ} \mathrm{C}$

Condenser outer temperature, ${ }^{\circ} \mathrm{C}$

External air temperature, ${ }^{\circ} \mathrm{C}$

Evaporator inlet temperature, ${ }^{\circ} \mathrm{C}$

Evaporator outer temperature, ${ }^{\circ} \mathrm{C}$

Evaporator outer temperature at nominal conditions, ${ }^{\circ} \mathrm{C}$

Maximum/minimum evaporator outer temperature, ${ }^{\circ} \mathrm{C}$

External air wet bulb temperature, ${ }^{\circ} \mathrm{C}$

Inlet fluid temperature, ${ }^{\circ} \mathrm{C}$

Set point fluid temperature, ${ }^{\circ} \mathrm{C}$

Inlet temperature at standard rating conditions at full load, ${ }^{\circ} \mathrm{C}$

Outlet temperature at standard rating conditions at full load, ${ }^{\circ} \mathrm{C}$

Reference mean water temperature at full, intermediate and zero load, ${ }^{\circ} \mathrm{C}$

Generator average water temperature (or return temperature to the generator for 


$\begin{array}{ll} & \text { condensing boilers) as a function of the specific operating conditions, }{ }^{\circ} \mathrm{C} \\ \rho_{\text {water }} & \text { Water density, } \mathrm{kg} / \mathrm{m}^{3} \\ \Phi_{\mathrm{C}} & \text { Nominal thermal power, } \mathrm{kW}\end{array}$

\section{References}

1. European Commission. Mandate to CEN, CENELEC and ETSI for the elaboration and adoption of standards for a methodology calculating the integrated energy performance of buildings and promoting the energy efficiency of buildings, in accordance with the terms set in the recast of the Directive on the energy performance of buildings (2010/31/EU). Mandate M 480 (2010)

2. European Parliament. Directive 2010/31/EU of the European Parliament and of the Council of 19 May 2010 on the energy performance of buildings (2010)

3. European Commission. Mandate to CEN, CENELEC and ETSI for the elaboration and adoption of standards for a methodology calculating the integrated energy performance of buildings and estimating the environmental impact. Mandate M 343 (2004)

4. A. Mattarelli, S. Piva. EN 15316 Calculation methods for the generation sub-system: the influence of input data on the results. Energy Procedia 45 (2014)

5. European Committee for Standardization (CEN). Energy performance of buildings Method for calculation of system energy requirements and system efficiencies - Part 42: Space heating generation systems, heat pump systems, Module M3-8-2, M8-8-2. EN 15316-4-2 Standard (2017)

6. Comitato Termotecnico Italiano (CTI). Document n. 025100365, prUNI/TS 11300-X-X draft. Prestazione energetica degli edifici - Metodo per il calcolo delle richieste di energia e delle efficienze del sistema - Sistemi di generazione per il riscaldamento degli ambienti, pompe di calore, Moduli italiani M3-8-2, M8-8-2 (2018)

7. Ente Nazionale Italiano di Unificazione (UNI). Energy performance of buildings - Part 4: Renewable energy and other generation systems for space heating and domestic hot water production. UNI/TS 11300-4 Standard (2016)

8. European Committee for Standardization (CEN). Energy performance of buildings Ventilation for buildings - Part 13: Calculation of cooling systems (Module M4-8) Generation. EN 16798-13 Standard (2017)

9. European Committee for Standardization (CEN). Energy performance of buildings Method for calculation of system energy requirements and system efficiencies - Part 41: Space heating and DHW generation systems, combustion systems (boilers, biomass), Module M3-8-1, M8-8-1 EN 15316-4-1 Standard (2017) 